\title{
Using rapid diagnostic tests as source of malaria parasite DNA for molecular analyses in the era of declining malaria prevalence
}

Deus S Ishengoma ${ }^{1 *}$, Sudi Lwitiho¹, Rashid A Madebe ${ }^{1}$, Nyagonde Nyagonde1, Ola Persson², Lasse S Vestergaard², Ib C Bygbjerg ${ }^{2}$, Martha M Lemnge ${ }^{1}$, Michael Alifrangis ${ }^{2}$

\begin{abstract}
Background: Malaria prevalence has recently declined markedly in many parts of Tanzania and other sub-Saharan African countries due to scaling-up of control interventions including more efficient treatment regimens (e.g. artemisinin-based combination therapy) and insecticide-treated bed nets. Although continued molecular surveillance of malaria parasites is important to early identify emerging anti-malarial drug resistance, it is becoming increasingly difficult to obtain parasite samples from ongoing studies, such as routine drug efficacy trials. To explore other sources of parasite DNA, this study was conducted to examine if sufficient DNA could be successfully extracted from malaria rapid diagnostic tests (RDTs), used and collected as part of routine case management services in health facilities, and thus forming the basis for molecular analyses, surveillance and quality control (QC) testing of RDTs.
\end{abstract}

Methods: One hyper-parasitaemic blood sample (131,260 asexual parasites/ $\mu l)$ was serially diluted in triplicates with whole blood and blotted on RDTs. DNA was extracted from the RDT dilution series, either immediately or after storage for one month at room temperature. The extracted DNA was amplified using a nested PCR method for Plasmodium species detection. Additionally, 165 archived RDTs obtained from ongoing malaria studies were analysed to determine the amplification success and test applicability of RDT for QC testing.

Results: DNA was successfully extracted and amplified from the three sets of RDT dilution series and the minimum detection limit of PCR was $<1$ asexual parasite/ $\mu$ l. DNA was also successfully amplified from (1) 70/71 (98.6\%) archived positive RDTs (RDTs and microscopy positive) (2) 52/63 (82.5\%) false negative RDTs (negative by RDTs but positive by microscopy) and (3) 4/24 (16.7\%) false positive RDTs (positive by RDTs but negative by microscopy). Finally, 7(100\%) negative RDTs (negative by RDTs and microscopy) were also negative by PCR.

Conclusion: This study showed that DNA extracted from archived RDTs can be successfully amplified by PCR and used for detection of malaria parasites. Since Tanzania is planning to introduce RDTs in all health facilities (and possibly also at community level), availability of archived RDTs will provide an alternative source of DNA for genetic studies such as continued surveillance of parasite resistance to anti-malarial drugs. The DNA obtained from RDTs can also be used for QC testing by detecting malaria parasites using PCR in places without facilities for microscopy.

\section{Background}

Malaria has for a long time remained a major cause of morbidity and mortality in most endemic countries particularly in sub-Saharan Africa. However, recent reports have indicated that malaria prevalence has declined

\footnotetext{
* Correspondence: dishengoma@tanga.mimcom.net

'National Institute for Medical Research, Tanga Centre, Bombo Road, P.O Box 5004, Tanga, Tanzania

Full list of author information is available at the end of the article
}

drastically in some endemic countries [1-4]. The decline has also been reported in most areas of Tanga region, which was a malaria hyper-endemic area until recently [5] and possibly other parts of Tanzania (National Malaria Control Programme, unpublished data). The declining malaria in Tanga, Tanzania and other countries is possibly attributed to more efficient treatment 
regimens (using artemisinin combination therapy, ACT) and increased availability and use of insecticide-impregnated bed nets[4].

Following changes of malaria treatment guidelines in Tanzania in 2006, by introducing an ACT containing artemether and lumefantrine (ALu) [6], which is relatively expensive compared to other drugs that were previously used in the country, it is rationally recommended that ALu should be prescribed to only laboratory confirmed cases $[7,8]$. However, laboratory services are not available in most parts of Tanzania, especially in rural areas and in places with laboratory facilities, the quality of malaria diagnosis is generally poor $[9,10]$ or the results are often ignored by clinicians [11]. Thus, the Tanzanian Ministry of Health and Social Welfare through the National Malaria Control Programme (NMCP) is planning to introduce rapid diagnostic tests (RDTs) in all health facilities to scale-up malaria diagnosis and improve case management.

RDTs detect presence of parasite specific antigens and available RDTs detect either Plasmodium falciparum specific histidine rich protein 2 (PfHRP-2), Plasmodium lactate dehydrogenase (pLDH) or aldolase [12-14]. Most of the available tests usually involve blotting a small volume of blood (2-20 $\mu \mathrm{l})$ on a nitrocellulose strip containing monoclonal antibodies, which react with parasite specific antigens available in the blood of infected patients to give visible, diagnostic and control bands [13]. Despite variability observed in field studies conducted in different settings [15-18], majority of RDTs have high sensitivity and specificity $(>90 \%)$ at a parasitaemia $>100$ asexual parasites/ $\mu \mathrm{l}$ [13]. The accuracy (sensitivity and specificity) of RDTs is mostly dependent on the parasite species, transmission intensity, parasite density, amount of circulating antigens, local polymorphisms of target antigen and persistence of antigens after treatment $[12,14]$.

Previous genetic studies of malaria parasites have largely relied on extraction of DNA from samples blotted on filter papers $[19,20]$. The filter papers have usually been easily sampled, for instance as part of drug efficacy trials and general assessments of malaria epidemiology and thus been a reliable source of parasite DNA. However, recently it has become increasingly difficult to obtain parasite samples due to declining malaria in most areas of Tanzania resulting in fewer studies performed, for instance drug efficacy studies. Moreover, the number of parasite positive patients from ongoing trials furthermore limits the sample size available for genetic studies. Despite the decrease in malaria prevalence, it is important for instance to identify emerging drug resistance and to update the molecular anti-malarial resistance maps that are currently being drawn, using sensitive molecular tools.
Alternatively, stained blood smears can be used to recover DNA but the quality of DNA is often low compared to filter papers or whole blood samples [21,22], because the harsh fixation and coloration procedures when preparing a Giemsa-stained smear may hamper extraction and amplification. A study which was conducted in French Guiana showed that parasite DNA could be recovered from fresh and archived RDTs [23]. However, more elaborate studies have not been conducted under different epidemiological and climatic settings to confirm if it is practically possible to recover parasite or human DNA from RDTs (either fresh tests or after extended storage). On the other hand, using RDT widely, even at the community level, is an obvious opportunity to obtain blood for diagnosis as well as storage, and later analysis for detection of resistance gene mutations or co-morbidities. Filter paper is widely used for the latter purpose, but not for diagnosis. Furthermore, the World Health Organization (WHO) recommendations for performing quality assurance (QA) of RDTs requires among other things, that RDTs should be monitored in the field by comparing the results of RDTs and reference microscopy monthly (for 20 blood smears with positive RDT results and 20 with negative results from selected sentinel sites) [24]. However, studies conducted to assess RDT implementation and QC monitoring strategies in malaria endemic areas have revealed that these recommendation cannot be attained due to lack of high quality diagnostic services by microscopy $[17,25]$, and thus different strategies such as using DNA extracted from RDTs for detection of malaria parasites will be needed to achieve the intended goal $[17,24,25]$.

This study was therefore conducted to establish if sufficient parasite DNA could be successfully extracted from different types of fresh and archived RDTs (stored at room temperature in the field/laboratory without any preservatives), and used for molecular analyses. It also explored the potentials of using RDTs as source of DNA for detection of malaria parasites as part of QC testing once the tests will be widely deployed in most health facilities in Tanzania. It is expected that availability of used RDTs will make it possible to obtain sufficient parasite samples and utilize them as sources of DNA for different molecular studies of malaria parasites and supporting the NMCP to perform QC testing of the RDTs that will be deployed in the field.

\section{Methods}

\section{Study site and sampling}

This study was conducted at Amani Biomedical Research Laboratory (AMBRELA) of the National Institute for Medical Research (NIMR) at Tanga Centre in Tanga region, northeastern Tanzania. Archived RDTs were 
obtained from ongoing studies in Muheza (Interactions between ACT for malaria and anti-retrovirals for HIV/AIDS in co-infected patients in Muheza district, Tanzania - InterACT project) and Korogwe [Passive case detection of fevers using community owned resource persons - CORPs (Ishengoma et al, personal communication)] districts of Tanga region, Tanzania.

\section{Samples and laboratory analysis}

A hyper-parasitaemic blood sample (with a parasite density of 131,260 asexual parasites/ $\mu \mathrm{l}$ ) obtained from a patient attended at Tumaini Health Centre in Tanga was initially diluted to 1,000 asexual parasites/ $\mu$ l with whole blood donated by uninfected donor (with blood group $\mathrm{O}^{+}$) and serially diluted (two fold dilutions in triplicate) to 0.01 asexual parasites/ $\mu$ l. About $10 \mu \mathrm{l}$ of the diluted samples were blotted on RDTs according to manufacturers' instructions (ParaHIT ${ }^{\circledR} \mathrm{f}$, Span Diagnostics - Surat, India). One set of the RDTs obtained from the serially diluted samples was immediately used for DNA extraction while two sets were stored at room temperature for a period of one month; one of these had silica preservatives added.

Before DNA extraction, the RDTs cassettes were opened using a sterile scissors and forceps, and the nitrocellulose strips were taken out. The strips were cut into two pieces and the portions containing the sample blotting site were used for extraction. The portions of RDTs that were used for DNA extraction were incubated in $0.5 \%$ saponin (in $1 \mathrm{X}$ phosphate buffered saline) over-night at room temperature. DNA extraction was performed as for filter papers using Chelex-100 method as previously described [26]. The extraction process was similar for the three sets of RDTs (either immediately or after storage at room temperature for one month, with/ without silica preservatives) and DNA was amplified using a nested PCR method for Plasmodium species detection according to Snonou et al [27]. Amplified products were visualized on $2 \%$ agarose gel.

A total of 165 archived RDTs were tested to confirm if DNA can be equally obtained from archived RDTs used for patients' diagnosis under routine clinical settings. The same RDTs were used to assess if they could be utilized as a source of DNA for detection of malaria parasites as part of QC testing of RDTs that will be deployed and used for malaria diagnosis at all levels of health care delivery system in Tanzania. The current QC testing of RDTs requires that 20 blood smears prepared by health workers at selected health facilities from patients with positive and 20 from those with negative RDT results should be examined by experienced technicians at a reference laboratory. However, in health facilities without the capacity for malaria diagnosis by microscopy, health workers cannot prepare blood smears of desirable quality and thus, archived RDTs can potentially be employed as an alternative to microscopy by using DNA extracted from such RDTs to detect malaria parasites. To test if DNA obtained from archived RDTs can be used for detection of molecular markers of anti-malarial drug resistance, DNA from one set of the serial dilutions and 10 archived RDTs were used for detection of parasite genotypes in the Pfdhfr gene which is a marker of pyrimethamine resistance using the method described by Alifrangis et al [28]

The archived RDT samples included 71 RDTs (positive for both RDT and microcopy) collected at health facilities in Muheza and Korogwe districts and stored without any preservatives at room temperature (temperature ranging from $25-34^{\circ} \mathrm{C}$ ). Out of these, 26 RDTs were obtained from patients enrolled in InterACT project in Muheza (on Paracheck Pf ${ }^{\mathbb{R}}$, Orchid Biomedical Systems - Mumbai, India) while 45 were from patients attended by CORPs in Korogwe district [on ParaHIT ${ }^{\circledR}$ f Span Diagnostics - Surat, India (Ishengoma et al, personal communication)]. Other 94 RDT samples (on ParaHIT ${ }^{\circledR}$ f), included 24 RDT false positive (positive by RDT but negative by microscopy), 63 false negatives (negative by RDTs but positive by microscopy) and seven negative samples (negative by both RDTs and microcopy) obtained from a cross-sectional survey conducted in May 2010 in four villages in Muheza district where high level of false positive and negative RDT results were observed in previous surveys (Ishengoma et $a l$, personal communication). All 165 RDT samples were stored at room temperature in the field or laboratory for a duration of 6 - 95 days (Table 1). DNA extraction and PCR genotyping were performed as in the previous assays mentioned above on individual tubes or 96-well plates depending on the number of samples.

\section{Results}

The minimum parasite detection limit of RDTs for the diluted samples was 10 asexual parasites/ $\mu$ l. DNA was successfully amplified from all of the three sets of RDTs containing the dilution series. RDT samples stored at room temperature for one month either with or without silica gels were amplified equally well, as fresh RDTs analysed immediately after blotting. The minimum parasite detection limit of PCR for all three sets of diluted samples was $<1$ asexual parasite/ $\mu$ l (Figure $1 \mathrm{~A}$ and $1 \mathrm{~B}$ ).

Table 1 shows the results of PCR amplification success for DNA extracted from different types of RDTs. Successful amplification was obtained from most of the microscopically positive samples whereby, 70 (98.6\%) out of 71 samples, which were positive by both microscopy and RDTs were detected to be positive by PCR (Figure 2A and 2B). Out of these, 26 (100\%) RDTs were Paracheck $\mathrm{Pf}^{\circledR}$ and $44(97.8 \%)$ were ParaHIT ${ }^{\circledR} \mathrm{f}$ 
Table 1 PCR amplification success of DNA extracted from different types/brand of archived RDTs

\begin{tabular}{|c|c|c|c|c|c|}
\hline \multirow[t]{2}{*}{ Category of RDTs sampled } & \multirow[t]{2}{*}{ No. of RDTs } & \multirow[t]{2}{*}{ Type/brand of RDT } & \multirow[t]{2}{*}{ Mean storage duration in days(range) } & \multicolumn{2}{|c|}{ PCR results } \\
\hline & & & & Positive (\%) & Negative (\%) \\
\hline True positive: RDT +ve/BS +ve & 26 & Paracheck Pf ${ }^{\circledR}$ & $28(7-58)$ & $26(100)$ & $0(0)$ \\
\hline True positive: RDT + ve/BS +ve & 45 & ParaHIT ${ }^{{ }_{f}} \mathrm{f}$ & $47(6-95)$ & $44(97.8)$ & $1(2.2)$ \\
\hline False negative: RDT -ve/BS +ve & 63 & ParaHIT ${ }^{\circledR} f$ & $60(61-66)$ & $52(82.5)$ & $11(17.4)^{*}$ \\
\hline False positive: RDT +ve/BS -ve & 24 & ParaHIT ${ }^{\circledR} f$ & $60(55-66)$ & $4(16.7)$ & $20(83.3)$ \\
\hline True negative: RDT -ve/BS -ve & 7 & ParaHIT ${ }^{\circledR} f$ & $65(63-69)$ & $0(0)$ & $7(100)$ \\
\hline
\end{tabular}

RDT = Rapid Diagnostic Test, BS = Blood smear, +ve = positive and -ve = negative.

*These samples had low parasite density detected by microscopy (less than 100 asexual parasites/ $\mu$; ranged from 16-80 asexual parasites/ $\mu$ l).

(Table 1). One positive RDT sample (ParaHIT $\left.{ }^{\circledR} \mathrm{f}\right)$, which failed to amplify by PCR, had a low parasitaemia detected by microscopy (one asexual parasite/200WBCs equivalent to 40 asexual parasites/ $\mu \mathrm{l})$. Fifty-two $(82.5 \%)$ of the 63 false negative RDTs (which were negative by RDTs, but positive by microscopy as a gold standard) were positive by PCR. Eleven (17.4\%) of the 63 false negative RDT samples which failed to amplify by PCR had low parasite density detected by microscopy (less than 100 asexual parasites/ $\mu$; ranged from $16-80$ asexual parasites $/ \mu \mathrm{l})$.
Detection of microscopically negative samples was equally successful whereby, 20 out of 24 (83.3\%) RDT false positive samples (which were positive by RDTs but negative by microscopy) were confirmed to be negative by PCR. Fourteen out of the 20 RDT false positive samples with negative PCR results were obtained from individuals who had taken anti-malarials (within seven days) before the survey. All seven negative RDTs (negative by both RDTs and microscopy) were also negative by PCR (Table 1). Detection of parasite genotypes for Pfdhfr gene as a marker of pyrimethamine resistance using

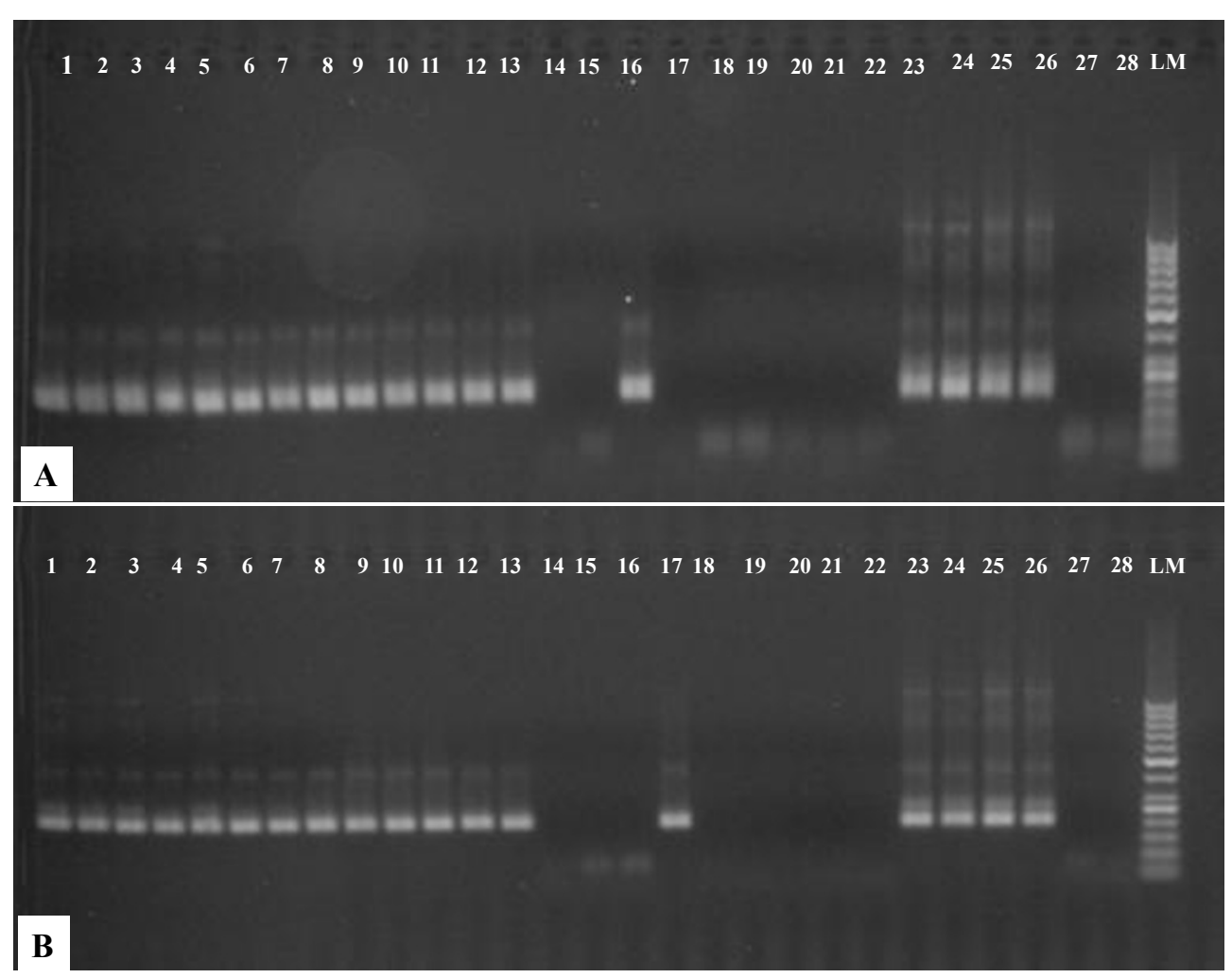

Figure 1 Pictures of agarose gels showing PCR products of DNA obtained from a hyper-parasitaemic sample which was blotted on RDTs after making two fold serial dilutions (from 1000 to 0.01 asexual parasites/ $\mu$ l) and extracted after storage at room temperature for 30 days with (A) or without (B) silica gels as preservatives. Lanes 1-22 = DNA from serially diluted samples, $23-26=$ positive controls (3D7 strain, 7g8 strain, patient sample with 1000 asexual parasites/ $\mu \mathrm{l}$, field sample on filter paper), 27-28 = negative controls and $\mathrm{LM}=50 \mathrm{pb}$ ladder marker. 


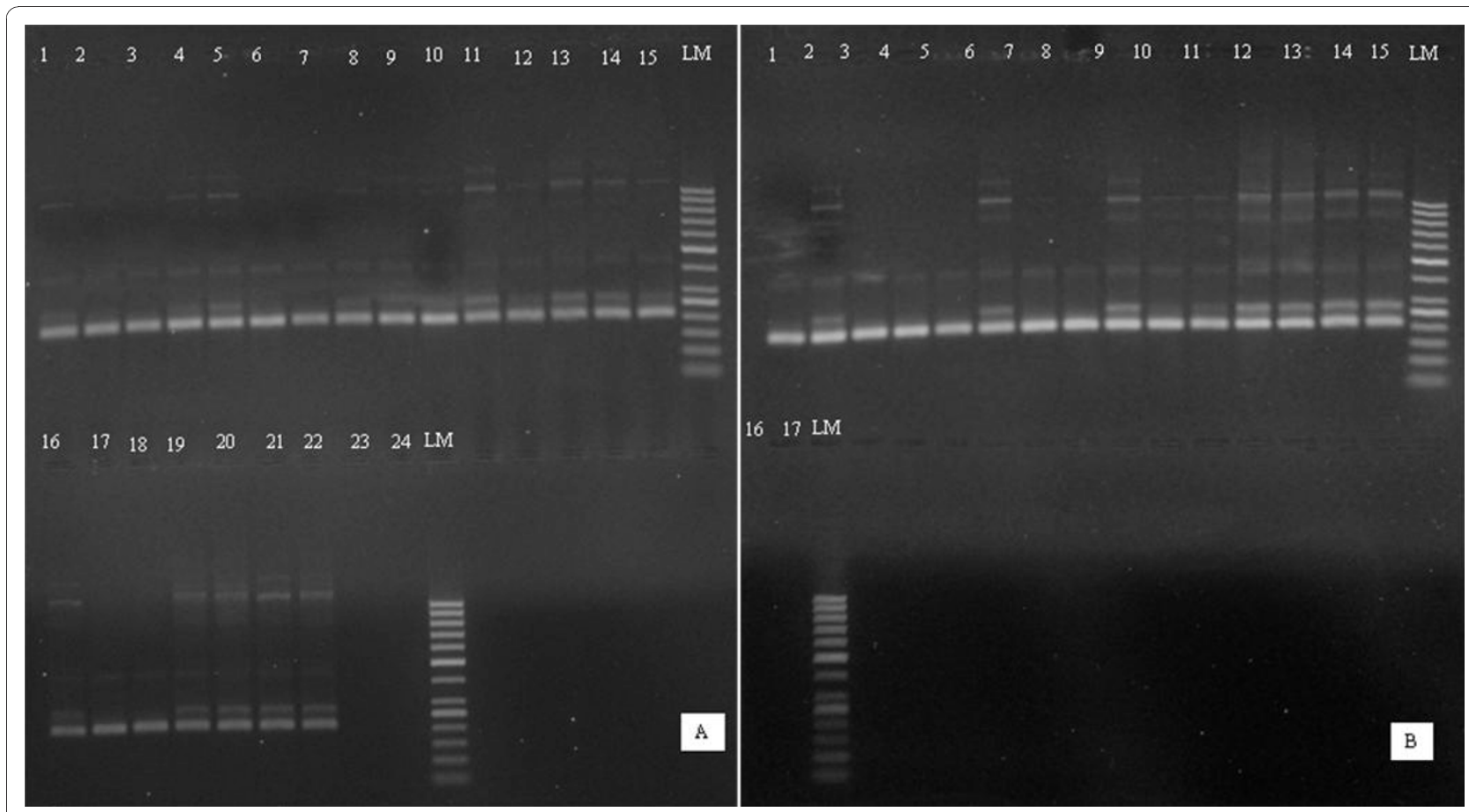

Figure 2 Selected pictures of agarose gels showing PCR amplification of DNA obtained from 29 of the 71 archived positive RDTs that were used for patients' diagnosis in Muheza and Korogwe districts. 2A: lanes 1-18 = field samples (16 from InterACT in Muheza in lanes 113 and 16-18, and 2 from Korogwe in lanes 14-15), 19-22 = positive controls (3D7strain, FCR3 strain, field sample on filter paper and patient sample with 1000 asexual parasites/ $\mu$ l), 23-24 = negative controls; $L M=50$ bp ladder marker 2B: lanes 1-11 = field samples (10 from InterACT in 1-10 and 1 from Korogwe in lane 11); 12-15 = positive controls (3D7 strain, FCR3 strain, field sample on filter paper and patient sample with 1000 asexual parasites/ $\mu \mathrm{l}), 16-17=$ negative controls and $L M=50$ bp ladder marker

DNA extracted from RDTs was also successful and the results were similar to those observed when DNA was obtained from other sources such as cultured parasites or filter papers.

\section{Discussion}

Previously, malaria has consecutively been shown to be the main cause of morbidity and mortality in Tanga region, as for the rest of Tanzania [29-31]. However, recently a drastic decline in the burden of malaria in this region has been reported [5]; (Ishengoma et al, personal communication) and most likely, the decline is apparent in other parts of Tanzania as well (NMCP, Unpublished data). However, because of this current positive trend, recruitment of malaria positive patients for various studies, such as malaria drug efficacy trials has proved to be difficult. Since the region has been known as a hotspot for the emergence of anti-malarial drug resistance in Eastern Africa [32-36], it is of paramount importance to continue the surveillance of in-vivo efficacy of principal anti-malarial drugs in the region. Research-wise, this is furthermore affecting the ability to obtain sufficient number of malaria parasite samples for different molecular studies such as studies on surveillance of molecular markers of anti-malarial drug resistance.

In this context, the study presented here has shown that archived RDTs used for malaria diagnosis in routine practice can be used as an alternative source of DNA for detection of malaria parasites and other molecular analyses. The RDTs can also be used as source of DNA as part of QC testing of RDTs instead of microscopic examination of Giemsa-stained blood smears, by comparing RTD results produced by health workers with those obtained in the laboratory based on detection of malaria parasite by PCR. Thus, after deployment of RDTs in the field, archived RDTs can also be used for QC of RDTs in addition to using Giemsa-stained blood smears, particularly in health facilities without capacity for performing malaria diagnosis by microscopy or lacking the skills and experience to prepare good blood smears as recently shown in Eastern Tanzania by McMorrow and colleagues [17,25].

Storage of RDTs (that were prepared in the laboratory) for one month either with or without silica gel as preservatives did not affect the quality of extracted DNA as determined by the detection limit of PCR in the diluted samples and band intensity of amplified products 
in comparison to known standard DNA samples which were used as control. Similarly, field samples stored at room temperature without preservatives for over 3 months were equally amplified. However, the impact of long term storage of RDTs beyond this duration on the quantity and quality of DNA is not clearly known, particularly if they are stored at room temperature without preservatives and under high ambient temperature, and humidity (as in most parts of Tanzania) which support growth of moulds that can degrade the parasite DNA. The period of three months or more shown in this and a previous study [23] should be sufficient to have the RDTs delivered to the laboratory even from the most remotely located parts of Tanzania.

Both types of PfHRP-2 based RDTs (ParaHIT ${ }^{\circledR} \mathrm{f}$ and Paracheck $\mathrm{Pf}^{(\mathbb{B}}$ ) examined provided DNA of sufficient quality with similar amplification success although the quantity of DNA was not assessed. This is in concordance to a previous study which showed that the type/ brand of RDTs did not affect the quality of extracted DNA [23]. Furthermore, the technique proved useful in examining conflicting diagnostic outcomes between microscopy and RDTs. RDT false positive samples showed similar results between PCR and microscopy indicating that most of the samples that were microscopically negative but positive by RDTs were actually negative. False positive results by PfHRP-2 based RDTs are commonly observed due to persistence of the antigens for over 30 days after clearance of parasites following treatment [37]. Among the 24 individuals with false positive RDT results, 14 had taken anti-malarials within seven days before the study; indicating that they may still had persistent PfHRP-2 antigens in their blood. PCR analysis of false negative samples showed conflicting results regarding a subset of samples (11 samples) initially identified by microscopy as positive (but negative by RDTs) and found to be negative by PCR. This could be due to low parasite density since all of these samples had $<100$ asexual parasites/ $\mu$ l which is the lowest detection limit of most of the RDTs and also within the lower detection limit of microscopy [13].

\section{Conclusion}

This study showed that DNA can be extracted from routinely used and archived RDTs, and successfully amplified by PCR; thus providing an alternative source of DNA for detection of malaria parasites and possibly other molecular analyses such as surveillance of parasite resistance to anti-malarial drugs and monitoring of insidious parasite reservoirs in different interventions, such as malaria elimination programmes. Furthermore, the RDTs can be used for QC testing of RDTs deployed in the field for malaria diagnosis based on comparing the results obtained by PCR genotyping of DNA extracted from archived RDTs with the test results produced by health workers, particularly from remotely located health facilities without the capacity of microscopic examination of blood smears. Thus, availability of archived RDTs after the tests are deployed in all health facilities in Tanzania as planned by the Ministry of Health and Social Welfare will provide a good source of parasite DNA for laboratory studies.

\section{Abbreviations}

ACT: artemisinin combination therapy; DNA: deoxyribonucleic acid; pLDH: Plasmodium lactate dehydrogenase; NIMR: National Institute for Medical Research; NMCP: National Malaria Control Programme; PCR: polymerase chain reaction; Pf: Plasmodium falciparum; PfHRP-2: Plasmodium falciparum histidine rich protein 2; RDTs: Rapid diagnostic tests; WBCs: white blood cells; WHO: World Health Organisation; $\mu$ l: microlitre.

\section{Acknowledgements}

The authors wish to thank the patients and the blood donor who donated the samples and field staff for collecting and processing the RDTs. Investigators of community studies in Korogwe district (Ezekiel Malecela, Johari Sadi and Tanga team) are greatly acknowledged for providing archived RDTs. The support provided by NIMR and other projects' staff is highly appreciated. This work has been partly supported by the ACT Consortium (which is funded through a grant from the Bill \& Melinda Gates Foundation to the London School of Hygiene and Tropical Medicine) and the Danish International Development Agency (DANIDA) through project No. N_08_KU.

\section{Author details}

${ }^{1}$ National Institute for Medical Research, Tanga Centre, Bombo Road, P.O Box 5004, Tanga, Tanzania. ${ }^{2}$ Centre for Medical Parasitology at the Department of International Health, Immunology and Microbiology, University of

Copenhagen and Department of Infectious Diseases, Copenhagen University Hospital (Rigshospitalet), Denmark.

\section{Authors' contributions}

DSI, MA conceived of the study, designed the experiments, supervised the laboratory analyses and wrote the manuscript. NN, OP and LV participated in study design and supplied archived RDTs while SL and RAM conducted the laboratory analyses. MML and ICB participated in study design and supervised the study. All authors read and approved the manuscript.

\section{Competing interests}

The authors declare that they have no competing interests.

Received: 9 October 2010 Accepted: 12 January 2011

Published: 12 January 2011

\section{References}

1. Ceesay SJ, Casals-Pascual C, Erskine J, Anya SE, Duah NO, Fulford AJ, Sesay SS, Abubakar I, Dunyo S, Sey O, Palmer A, Fofana M, Corrah T, Bojang KA, Whittle HC, Greenwood BM, Conway DJ: Changes in malaria indices between 1999 and 2007 in The Gambia: a retrospective analysis. Lancet 2008, 372:1545-1554.

2. Ceesay SJ, Casals-Pascual C, Nwakanma DC, Walther M, Gomez-Escobar N, Fulford AJ, Takem EN, Nogaro S, Bojang KA, Corrah T, Jaye MC, Taal MA, Sonko AA, Conway DJ: Continued decline of malaria in The Gambia with implications for elimination. PLOS ONE 2010, 5:e12242.

3. Okech BA, Mwobobia IK, Kamau A, Muiruri S, Mutiso N, Nyambura J, Mwatele C, Amano T, Mwandawiro CS: Use of integrated malaria management reduces malaria in Kenya. PLOS ONE 2008, 3:e4050.

4. WHO: World Malaria Report 2009 Geneva, Switzerland, World Health Organization; 2009.

5. Mmbando BP, Vestergaard LS, Kitua AY, Lemnge MM, Theander TG, Lusingu JP: A progressive declining in the burden of malaria in northeastern Tanzania. Malar J 2010, 9:216. 
6. Ministry of Health: In National guidelines for malaria diagnosis and treatment. Edited by: Mwita A, Molten F. United Republic of Tanzania, Ministry of Health and Social Welfare; 2006:

7. WHO: Guidelines for the treatment of malaria Geneva, Switzerland, World Health Organization; 2006

8. WHO: Guidelines for the treatment of malaria. Second edition. Geneva, Switzerland, World Health Organization; 2010.

9. Ishengoma DR, Rwegoshora RT, Mdira KY, Kamugisha ML, Anga EO, Bygbjerg IC, Ronn AM, Magesa SM: Health laboratories in the Tanga region of Tanzania: the quality of diagnostic services for malaria and other communicable diseases. Ann Trop Med Parasitol 2009, 103:441-453.

10. Ishengoma DR, Derua YA, Rwegoshora RT, Tenu F, Massaga JJ, Mboera LE, Magesa SM: The performance of health laboratories and the quality of malaria diagnosis in six districts of Tanzania. Ann Trop Med Parasitol 2010, 104:123-135

11. Reyburn H, Mbakilwa H, Mwangi R, Mwerinde O, Olomi R, Drakeley C, Whitty CJ: Rapid diagnostic tests compared with malaria microscopy for guiding outpatient treatment of febrile illness in Tanzania: randomised trial. BMJ 2007, 334:403.

12. Bell D, Wongsrichanalai C, Barnwell JW: Ensuring quality and access for malaria diagnosis: how can it be achieved? Nat Rev Microbiol 2006, 4:682-695.

13. Moody A: Rapid diagnostic tests for malaria parasites. Clin Microbio/ Rev 2002, 15:66-78.

14. Murray CK, Gasser RA Jr, Magill AJ, Miller RS: Update on rapid diagnostic testing for malaria. Clin Microbiol Rev 2008, 21:97-110.

15. Chinkhumba J, Skarbinski J, Chilima B, Campbell C, Ewing V, San Joaquin M, Sande J, Ali D, Mathanga D: Comparative field performance and adherence to test results of four malaria rapid diagnostic tests among febrile patients more than five years of age in Blantyre, Malawi. Malar 2010, 9:209.

16. Kamugisha ML, Msangeni $\mathrm{H}$, Beale E, Malecela EK, Akida J, Ishengoma DR, Lemnge MM: Paracheck Pf compared with microscopy for diagnosis of Plasmodium falciparum malaria among children in Tanga City, northeastern Tanzania. Tanzan J Health Res 2008, 10:14-19.

17. McMorrow ML, Masanja Ml, Kahigwa E, Abdulla SM, Kachur SP: Quality assurance of rapid diagnostic tests for malaria in routine patient care in rural Tanzania. Am J Trop Med Hyg 2010, 82:151-155.

18. Wongsrichanalai C, Barcus MJ, Muth S, Sutamihardja A, Wernsdorfer WH: A review of malaria diagnostic tools: microscopy and rapid diagnostic test (RDT). Am J Trop Med Hyg 2007, 77:119-127.

19. Bereczky S, Martensson A, Gil JP, Farnert A: Short report: Rapid DNA extraction from archive blood spots on filter paper for genotyping of Plasmodium falciparum. Am J Trop Med Hyg 2005, 72:249-251.

20. Kain KC, Lanar DE: Determination of genetic variation within Plasmodium falciparum by using enzymatically amplified DNA from filter paper disks impregnated with whole blood. J Clin Microbiol 1991, 29:1171-1174.

21. Edoh D, Steiger S, Genton B, Beck HP: PCR amplification of DNA from malaria parasites on fixed and stained thick and thin blood films. Trans $R$ Soc Trop Med Hyg 1997, 91:361-363.

22. Scopel KK, Fontes CJ, Nunes AC, Horta MF, Braga EM: Low sensitivity of nested PCR using Plasmodium DNA extracted from stained thick blood smears: an epidemiological retrospective study among subjects with low parasitaemia in an endemic area of the Brazilian Amazon region. Malar $J$ 2004, 3:8.

23. Veron V, Carme B: Recovery and use of Plasmodium DNA from malaria rapid diagnostic tests. Am J Trop Med Hyg 2006, 74:941-943.

24. WHO: Quality Assurance of Malaria Rapid Diagnostic Tests: Buying well and maintaining accuracy Geneva, Switzerland., World Health Organisation; 2008.

25. McMorrow ML, Masanja MI, Abdulla SM, Kahigwa E, Kachur SP: Challenges in routine implementation and quality control of rapid diagnostic tests for malaria-Rufiji District, Tanzania. Am J Trop Med Hyg 2008, 79:385-390.

26. Wooden J, Kyes S, Sibley CH: PCR and strain identification in Plasmodium falciparum. Parasitol Today 1993, 9:303-305.

27. Snounou G, Viriyakosol S, Jarra W, Thaithong S, Brown KN: Identification of the four human malaria parasite species in field samples by the polymerase chain reaction and detection of a high prevalence of mixed infections. Mol Biochem Parasitol 1993, 58.283-292.

28. Alifrangis M, Enosse S, Pearce R, Drakeley C, Roper C, Khalil IF, Nkya WM, Ronn AM, Theander TG, Bygbjerg IC: A simple, high-throughput method to detect Plasmodium falciparum single nucleotide polymorphisms in the dihydrofolate reductase, dihydropteroate synthase, and $P$. falciparum chloroquine resistance transporter genes using polymerase chain reaction- and enzyme-linked immunosorbent assay-based technology. Am J Trop Med Hyg 2005, 72:155-162.

29. Ellman R, Maxwell C, Finch R, Shayo D: Malaria and anaemia at different altitudes in the Muheza district of Tanzania: childhood morbidity in relation to level of exposure to infection. Ann Trop Med Parasitol 1998 92:741-753.

30. Kamugisha ML, Gesase S, Mlwilo TD, Mmbando BP, Segeja MD, Minja DT, Massaga JJ, Msangeni HA, Ishengoma DR, Lemnge MM: Malaria specific mortality in lowlands and highlands of Muheza district, north-eastern Tanzania. Tanzan Health Res Bull 2007, 9:32-37.

31. Mmbando BP, Segeja MD, Msangeni HA, Sembuche SH, Ishengoma DS, Seth MD, Francis F, Rutta AS, Kamugisha ML, Lemnge MM: Epidemiology of malaria in an area prepared for clinical trials in Korogwe, northeastern Tanzania. Malar J 2009, 8:165.

32. Clyde DF: Drug resistance of malaria parasites in Tanzania. East Afr Med J 1966, 43:405-408.

33. Alifrangis M, Lemnge MM, Ronn AM, Segeja MD, Magesa SM, Khalil IF, Bygbjerg IC: Increasing prevalence of wildtypes in the dihydrofolate reductase gene of Plasmodium falciparum in an area with high levels of sulfadoxine/pyrimethamine resistance after introduction of treated bed nets. Am J Trop Med Hyg 2003, 69:238-243.

34. Lemnge M, Alifrangis M, Kafuye MY, Segeja MD, Gesase S, Minja D, Massaga JJ, Ronn AM, Bygbjerg IC: High reinfection rate and treatment failures in children treated with amodiaquine for falciparum malaria in Muheza villages, Northeastern Tanzania. Am J Trop Med Hyg 2006, 75:188-193.

35. Mutabingwa T, Nzila A, Mberu E, Nduati E, Winstanley P, Hills E, Watkins W: Chlorproguanil-dapsone for treatment of drug-resistant falciparum malaria in Tanzania. Lancet 2001, 358:1218-1223.

36. Ronn AM, Msangeni HA, Mhina J, Wernsdorfer WH, Bygbjerg IC: High level of resistance of Plasmodium falciparum to sulfadoxine-pyrimethamine in children in Tanzania. Trans R Soc Trop Med Hyg 1996, 90:179-181.

37. Kyabayinze DJ, Tibenderana JK, Odong GW, Rwakimari JB, Counihan H: Operational accuracy and comparative persistent antigenicity of HRP2 rapid diagnostic tests for Plasmodium falciparum malaria in a hyperendemic region of Uganda. Malar J 2008, 7:221.

doi:10.1186/1475-2875-10-6

Cite this article as: Ishengoma et al:: Using rapid diagnostic tests as source of malaria parasite DNA for molecular analyses in the era of declining malaria prevalence. Malaria Journal 2011 10:6

\section{Submit your next manuscript to BioMed Central and take full advantage of:}

- Convenient online submission

- Thorough peer review

- No space constraints or color figure charges

- Immediate publication on acceptance

- Inclusion in PubMed, CAS, Scopus and Google Scholar

- Research which is freely available for redistribution 